\title{
RÉPLICA DE LOS AUTORES
}

Agradecemos sinceramente todos los cometarios recibidos y nos congratulamos del debate que entre todos hemos provocado, podríamos añadir, en un contexto académico no muy dado al intercambio plural y abierto de ideas y al toma y daca de la crítica constructiva.

Nuestro escrito tenía dos partes bien diferenciadas, una negativa y otra positiva. La primera denunciaba lo que no debía ser (pero en parte es) la sociología y la segunda proponía lo que debería ser, y en parte ya es. Todos nuestros comentaristas están básicamente de acuerdo en la primera parte; todos aceptan la oportunidad de la alerta lanzada y, desde luego, el pequeño análisis que hace el profesor Lamo de Espinosa del último Congreso Español de Sociología no invita demasiado a los diagnósticos optimistas. El profesor Giner considera "impecable" nuestro diagnóstico crítico, pero otros, como los profesores Enguita y Caínzos, son bastante más duros que nosotros mismos: el primero habla de "verborrea opiniática generalizada propia de este país de tertulianos" y de "toda una larga cola de sociología trivial", mientras que el segundo denigra "la influencia del tropel de charlatanes y vendedores de baratijas intelectuales". En un tono más neutro, el profesor Ovejero reconoce "el (mal) estado de buena parte de la llamada "teoría sociológica" mientras que a la profesora Durán le parece "muy pertinente" nuestro análisis. Finalmente, la profesora González de la Fe entiende la comunidad sociológica española como una colección de "tribus" y nuevamente explicita su acuerdo con nuestro diagnóstico.

Constatar un consenso entre sociólogos tan renombrados sobre lo que no se debe hacer es ya un paso muy importante y justificaría con creces nuestro escrito y la iniciativa de abrirlo a un debate. Tanto más cuanto que ese consenso se ha producido espontáneamente, pues ninguno de los invitados sabía por nosotros de la participación de los demás. Señalizar el camino de la ciencia social con ciertas prohibiciones y límites de velocidad puede evitar que algún que otro joven se extravíe por los callejones de algunas ocurrentes pseudogenialidades y se estrelle en el aplauso fácil de sus mayores.

Las dudas y las críticas se concentran, como era de esperar, en la parte positiva de nuestro manifiesto, esto es, en la propuesta propiamente dicha de un giro analítico para la sociología. Y aquí nos satisface comprobar cómo el consenso se desvanece, al menos en un punto: mientras unos creen acertada la sustancia de la propuesta analítica, pero discrepan de su tono y de la estrategia misma de proponerla, otros, en cambio, juzgan necesaria o conveniente la estrategia, aunque discrepen en algunas cuestiones sustantivas; e incluso entre éstos, mientras algunos consideran la propuesta excesivamente rígida, otros la ven excesivamente tibia.

A las dudas sobre tonos y estrategias, que siempre son, todo hay que decirlo, menos relevantes que las sustantivas (puesto que, aunque seguramente sobre decirlo, lo que proponemos es un debate epistémico y no político-estratégico), responderíamos dudando nosotros mismos sobre qué tonos y estrategias alternativas cabría utilizar para hacer frente a la situación que todos lamentamos, pues no parece que hasta ahora ninguna de ellas haya conseguido que la pseudo-sociología se bata en retirada o pierda su predicamento. 
Pero son las dudas sustantivas sobre la propuesta analítica las que más nos interesan. Obviamente no podemos contestar pormenorizadamente a todos los comentarios, pero intentaremos al menos considerar los principales. El reducido espacio disponible hará disculpar al lector y a nuestros comentaristas la parquedad y rapidez de algunas de nuestras observaciones, que dividiremos en varios grupos.

\section{1.- Ciencia, teoría y explicación}

El profesor Caínzos se rebela contra los intentos de "entronización" de "las explicaciones teóricamente fundadas como objetivo central -y, en el límite, único objetivo legítimo- de la investigación científico social" (p. 459). No queremos entronizaciones ni coronas y somos conscientes de la pluralidad de tareas implicadas en la investigación científica. Lo que decimos es que la ciencia social, como cualquier ciencia, tiene como tarea y aspiración primordial responder a preguntas por el por qué, buscar relaciones causales y comprenderlas mediante la aportación de mecanismos causales. Ello no implica en ningún caso desmerecer esas otras tareas de la actividad científica como la descripción, la medición, la clasificación, la formación de conceptos, la comparación, o la intervención. Lo que nos sorprende es la tajante separación que hace el profesor Caínzos entre esos quehaceres. A la inversa, estamos convencidos de que la falta de calidad de los datos empíricos con que a veces cuenta el sociólogo, o su insuficiencia, heterogeneidad o fragmentación se deben al insuficiente desarrollo teórico de las áreas de investigación afectadas. No concebimos la observación o la medición científicas sin teorías que nos indiquen lo que es relevante observar y medir. Como Marx, auguramos poco éxito a la predicción o la intervención social no basadas en teorías sólidas sobre las relaciones causales que rigen los fenómenos sociales relevantes. Y no vemos la descripción (operación previa imprescindible para que tenga sentido explicar algo) como fin último de una ciencia. Cuanto más sólidos sean los programas de investigación y más consolidados estén en torno a teorías solventes o prometedoras, mejores observaciones, mediciones, clasificaciones, comparaciones, predicciones e intervenciones sociales tendremos.

Una aclaración importante: estamos totalmente de acuerdo con el profesor Enguita en que la "analiticidad" de una teoría o hipótesis sociológica no garantiza su verdad, como no lo hace en ninguna otra ciencia. Lo que decimos no es, por descontado, que las teorías e hipótesis de la sociología analítica sean verdaderas por definición, sino que para decidir si una teoría o hipótesis es correcta y verdadera se debe proceder analíticamente, y no mediante instancias intuitivas, subjetivistas, ideológicas o impresionistas.

Permítasenos añadir, brevemente, varias pinceladas sobre las pretensiones epistémicas de la sociología analítica, que aclaren: a) que no entendemos el giro analítico, como sugiere Caínzos, como "algo diferente de una reafirmación del espíritu de rigor científico" (p. 459), y que su primera objeción se desvanece en cuanto se abandona la petitio principii de que sociología analítica y sociología científica son o pueden ser dos cosas distintas, y se entiende la primera no como una teoría única, sino como unas "reglas del juego" para formular teorías científico-sociales racionales; b) que nuestra apelación a 
la racionalidad epistémica, quizás algo ambigua, busca excluir los enfoques declaradamente irracionalistas e irrealistas que hoy campan por sus respetos en la disciplina; c) que el sentido cientíicamente relevante de los conceptos de "análisis" $y$ "síntesis" noes tanto el más ensayístico que proponía Spencer (y que cita el profesor Lamo), sino el que aparece en Wilson o Hedström (véase la nota 6 de nuestro texto), y, en ese sentido, que es el que nos interesa, las ciencias sociales no son en absoluto (ni seguramente podrán ser) sintéticas, como sí lo son cada vez más las naturales; d) que asumir la imposibilidad de extender un enfoque analítico a algún rango de los fenómenos sociales es no haber roto del todo con la creencia de que pueden existir misteriosas relaciones "esenciales" entre enfoques teóricos y ámbitos fenoménicos, creencia que toda ciencia que se precie ha superado (como la semántica racional no cree que exista una relación "mágica" entre palabras y objetos); e) que la enorme complejidad social hace más necesarios, no menos, el análisis y la reducción científicas; f) que el error del funcionalismo no fue pretender una saludable unidad paradigmática de la ciencia social, sino pretenderlo mediante un tipo de explicaciones teleológicas inaceptables; y, finalmente, g) que aunque es cierto que cierta "sociología ensayística" puede contener sugerencias e ideas interesantes (seguramente no más que la buena literatura), éstas sólo cobran relevancia científico-social (y no meramente estética) cuando son formuladas analíticamente e integradas en modelos teóricos rigurosos.

\section{2.- Teoría de la acción y de la mente}

La profesora González de la Fe plantea la pregunta de si la apelación a entidades inobservables directamente como los estados mentales no cuestiona las pretensiones científicas de la sociología analítica. Suscribimos totalmente la respuesta implícita a esa pregunta que da el profesor Ovejero en su intervención, que nos ahorra mayores precisiones, cosa que le agradecemos. Que los estados mentales no son directamente observables parece obvio; que tampoco lo son los electrones o la evolución de las especies por selección natural lo es igualmente, y no parece ser un problema para la cientificidad de la física o la biología. Las teorías científicas y sus derivaciones empíricas son maneras de decidir las cuestiones de existencia (siempre hasta nuevo aviso); las ciencias "prueban sus afirmaciones" así, contrastando hipótesis empíricas derivadas de teorías que incluyen algunas entidades inobservables directamente, y no vemos por qué la sociología debería ser diferente.

Del mismo modo, que las razones pueden ser las causas de las acciones nos parece inobjetable científicamente (la sociología analítica tiende a ser, sí, davidsoniana); lo que no nos parece de recibo es que una "teoría del sujeto" (sea basada en Pareto 0 cualquier otra) pueda decidir a priori que todas las acciones son causadas por emociones irracionales (o por cualquier otra cosa); como ha mostrado Elster, es una cuestión empírica la investigación de los mecanismos presentes en cada caso concreto de acción social (y éstos pueden involucrar racionalidad, normas o emociones); pretender resolverla de un plumazo con una teoría apriorística sería volver a la mala filosofía social especulativa que la sociología analítica busca relegar. 
De nuevo unas cuantas acotaciones pueden ser de utilidad para explicarnos mejor: la tradición analítica en filosofía de la mente, de la intencionalidad y del lenguaje dispone hoy día de una magnífica teorización (en muchos casos la discusión sigue abierta) sobre estas cuestiones, de calidad y finura a nuestro juicio sin rival en otras tradiciones (baste consultar las obras de Searle, Davidson o Kim). El llamado "giro lingüístico" resulta mucho más inteligible y fructífero si se formula con estas herramientas y se encuadra en dicho marco, y sus aplicaciones científicas a la sociología más prometedoras discurren por este camino más que por el de otras tradiciones quizá con más solera en la tradición sociológica "canónica", pero hoy día bastante estancadas e intelectualmente agotadas desde el punto de vista de su productividad científica. Finalmente, sobre el vínculo micro-macro cabe decir que si algo como el Coleman boat (reproducido en el artículo de F. Barbera que cita la profesora Durán, y aún hoy sorprendentemente poco conocido en nuestro país) no ayuda a resolver inteligiblemente la integración de ambos niveles (aunque en vez de "los otros pensantes" se hable simplemente de actores sociales), entonces no estará de más preguntarse qué otra cosa lo hará, y cómo.

Por cierto merece la pena añadir que la sociología analítica sigue utilizando conceptos que se refiren a objetos complejos correspondientes al nivel macro del esquema de Coleman (como los que cita el profesor Pérez Yruela), proscribiendo únicamente aquellos que carezcan de adecuados microfundamentos.

\section{3.- Sociología normativa}

Los valores son conceptos que nos permiten describir estados en principio posibles de la realidad que además son deseables. Si alguien dice " $X$ es una sociedad justa" o " $Y$ es una economía eficiente" o "Z es un grupo bien integrado" describe estados posibles en principio y deseables, respectivamente, de la sociedad $X$, de la economía $Y$ o del grupo Z. Sin embargo, para que esa descripción tenga sentido, necesitamos articular previamente -teóricamente- las nociones de justicia, de eficiencia o de integración. De lo contrario, la descripción sería vacía. La economía del bienestar o economía normativa ha explorado el principio de eficiencia y a nuestro entender ha generado un importante caudal de conocimiento y ha permitido fundar y desarrollar el juicio normativo de la disciplina económica (lo cual, sin duda, ha acabado teniendo consecuencias prácticas en parte de la política económica, aunque, como nota el profesor Ovejero, las aportaciones y logros más "técnicos" de la economía del bienestar no tengan por qué tenerlas forzosamente).

Nosotros pensamos que la sociología, como la economía, puede desarrollar una rama normativa. Construirla en torno al eje de la cohesión o la integración social no es más que un ejemplo. Y no vemos por qué el sociólogo tendría que ceder al economista, al biólogo evolutivo o al filósofo la articulación teórica de ese principio normativo. Dicha articulación, por otro lado, podría generar interesantes investigaciones empíricas. Sin ir más lejos, así ha ocurrido con el concepto de capital social, concepto sociológico donde los haya: su articulación teórico-normativa establece en qué condiciones puede ser deseable generarlo. Podría descubrirse -como de hecho cree haber descubierto 
Putnam- que bajo ciertas circunstancias el capital social dinamiza la economía y favorece el crecimiento. En otras, como en el caso de la mafia, favorece la integración pero sobre la base de una primitiva concepción de la justicia y de la resolución de conflictos en clara contradicción con intuiciones morales fundamentales y principios normativos bien asentados en nuestra cultura. Volviendo al ejemplo de la integración social, en principio todos preferimos una familia, un grupo, una sociedad bien integrados a la opción contraria. Por eso, la integración social es un buen candidato -aunque aquí sólo valga como ejemplo- para constituirse en eje de una posible sociología normativa. El problema es que, pese a que dicho concepto de integración -o sus posibles variantesestá bien instalado en la tradición sociológica, no sabemos realmente lo que significa, no está articulado teóricamente y, por eso, resulta difícil observarlo, medirlo, establecer tipos, hacer comparaciones, etc. Podríamos determinar con precisión las ineficiencias de la economía capitalista (también, por supuesto, de la centralmente planificada), sus injusticias básicas, pero no sus niveles de (des)integración: el desarrollo de una sociología normativa podría contribuir a superar esa brecha. Ésa sería la función de una sociología normativa (y no, como supone Caínzos, la de ser "fuente de normatividad" ética: en esto estamos de acuerdo con Weber, tal y como nuestro texto apuntaba).

\section{4.- Otros "cabos sueltos"}

En debates como el presente se suscitan tantas cuestiones y de tal calado que resulta imposible ventilarlas exhaustivamente. Aun así, no queremos finalizar sin aclarar nuestra posición ( 0 , al menos, sin dar las pistas pertinentes sobre la misma) acerca de algunas de las observaciones que nuestros incisivos interlocutores plantean. Para empezar, una acotación expositiva: hemos supuesto (quizá erróneamente) que las referencias ofrecidas y los dos monográficos de revista ya publicados en España sobre sociología analítica cumplían la función de una descripción más detallada y sistemática de los principios de dicha sociología y ejemplificaban sus actuales desarrollos. Por esa razón, hemos optado en este texto por abordar algunos debates recurrentes que suelen plantearse y casi nunca encuentran adecuado tratamiento (quizá por ello se ha suscitado una impresión de argumentar "a la defensiva"). Sin embargo, los principios detallados que algunos nos reclaman están suficientemente desarrollados en la literatura que referenciamos, aunque no los hayamos reproducido al milímetro en nuestro texto aquí, que no pasa de ser una presentación.

Permítasenos insistir en nuestra convicción de que la sociología analítica y su defensa sin complejos es el camino más prometedor de la sociología actual. Denunciar unas determinadas concepciones pseudo-cientíicas de la sociología, rastreables e identificables, no es ver "enemigos ubicuos", sino llamar a las cosas por su nombre. Difícilmente se puede compartir el diagnóstico sobre la situación actual de la sociología para, acto seguido, seguir contemporizando con el actual pseudo-pluralismo de "escuelas" y "paradigmas" que es una de sus principales causas; si de evitar "fundamentalismos cerrados" se trata, retamos a cualquier observador imparcial a comparar la sociología 
analítica actual con cualesquiera tradiciones sociológicas, en la confianza de que muchas de las que hoy se imparten alegremente en los programas de teoría sociológica cualifican mucho mejor para ocupar el puesto de "teorías fundamentalistas cerradas". Sobran referencias literales (pero falta aquí espacio para citarlas) que prueban fehacientemente que las confusiones que denunciamos y las tesis que combatimos son explícita y desvergonzadamente defendidas por corrientes y autores "consagrados" de la disciplina, y que los principios que hemos enumerado (y no sólo los dos favoritos del profesor Enguita) son rechazados por muchos de ellos. Como hemos repetido, no nos interesa discutir por palabras, pero si la toma de conciencia en favor de la cientificidad que defendemos no se puede denominar "analítica", no vemos qué otro calificativo la puede capturar mejor semánticamente hablando.

Es cierto, como nos recuerda el profesor Giner, que hay mucha sociología analítica (buena sociología) en los clásicos, pero también que no eran infalibles, que existen numerosas "cajas negras" en las explicaciones que dieron, y que si la mayoría de ellos hubiera tenido a su disposición innovaciones como la teoría de juegos, los modelos multi-agente, la experimentación conductual, las narrativas analíticas, la teoría de la acción colectiva, etc., se hubieran lanzado de cabeza a estudiarlas y utilizarlas.

Tiempo habrá de volver en detalle, con argumentos y evidencias, sobre muchos de estos puntos. En principio hemos creado un espacio para la discusión y el encuentro intelectual honesto y crítico, no un espacio cerrado y tribal. Creemos que es un espacio necesario porque hay multitud de problemas - de ontología social, de fundamentación epistemológica, de metodología y conceptualización, de construcción teórica, de contrastación empírica- que son susceptibles de tratamiento analítico. Esperamos que esos problemas generen, en efecto, "animadas reuniones de 'analíticos' discutiendo los trabajos de otros analíticos" (p. 462) y que esas discusiones tengan influencia a través de sus correspondientes publicaciones; mas no pretendemos hacer la guerra a nadie ni desplegar una cruzada in partibus infidelium como parece recomendarnos el profesor Caínzos. El grupo está abierto al científico positivo y al normativo, al filósofo social y al metodólogo. Hemos intentado fijar el perfil del grupo en el manifiesto que abre este debate. Agradecemos particularmente las palabras finales de Salvador Giner, en las que reconoce la conveniencia de defender la propuesta analítica en sociología, así como que ello "redundará al final en beneficio de la buena ciencia social" (p. 471). Y remachamos este clavo con la idea del profesor Ovejero de que, en la medida en que la sociología analítica tenga éxito, será menos necesario confiar en la honestidad intelectual individual, porque ésta vendrá institucionalmente garantizada: y esta idea, que Ovejero ha formulado mejor que nosotros, es, creemos, la principal razón ética para apoyar un giro analítico en sociología.

FERNANDO AGUIAR ANDRÉS DE FRANCISCO JOSÉ ANTONIO NOGUERA 